\title{
Objectively Measuring COVID-19 Transformations and Identifying Scalable Policy Determinants While Explicitly Accounting for The Influence of Culture
}

\author{
Chris D Beaumont ${ }^{1 *}$ Darrell Berry ${ }^{2}$ and John Ricketts ${ }^{2}$ \\ ${ }^{1}$ Institute for Future Initiatives, LifeStyle by Design, The University of Tokyo, Japan \\ ${ }^{2}$ Significance Systems, Sydney NSW 2069, Australia
}

Submission: March 05, 2021; Published: March 23, 2021

"Corresponding author: Chris D Beaumont, Institute for Future Initiatives, LifeStyle by Design, The University of Tokyo, 7-3-1 Hongo, Bunkyo-Ku, Tokyo 113-0033, Japan

\section{Abstract}

COVID-19 has moved health, in its broadest sense to the top of everyone's agenda. Narratives and media are integral parts of today's interconnected lives and increasingly shape our world. As healthy lifestyle choices become increasingly important, social sharing of new ideas and practices that gain credibility and engagement will have the potential to drive major behavioral shifts, as well as improve basic health literacy. This paper explores some transformational lifestyle narratives. Tracking what people feel is important at any point in time has implications for policymakers and private institutions, since such feelings can drive positive behavioural change. This ability, to understand what is important, in a timely manner, has never been more important since the outbreak of COVID-19. It provides a future orientation that can future-proof policy, at scale. Several key lifestyle narratives are tracked through Big Data and AI analyses, before and during the COVID-19 pandemic, comparing the dynamic situation in Japan and the UK. Most social media content is usually transient, but it is possible to identify timeless and transformational narratives that have utility and can affect change and create sustainable value.

Keywords: Narrative; Emotion; Transformational; Engagement; Virtual Living Lab

\section{Introduction}

The Life Style $e_{\text {by }}$ Design research initiative, at The University of Tokyo, seeks to promote and deliver healthier lifestyle behaviour bringing a new balance to the physical, nutritional and social needs to enhance an individual's QOL (Quality of Life). The mission of LifeStyle ${ }_{\text {by }}$ Design is to empower the individual to make an informed choice about their life options. For that to occur, improved health literacy will be required, with coherent communications describing new possibilities to multiple constituencies. Now, in most countries, diffusion of new ideas is greatly enhanced by the pervasive participation in social media using smart mobile devices. Indeed, stories and social media characterize our interconnected world and fuel our imagination. Shiller [1] looked at how the narratives we tell ourselves about the world drive our personal and economic behaviour, and thus the world itself if enough people change their attitudes and behaviour because of them. The internet has given voice all over the world to people and elevated new narratives that are based on cultural truths rather than rational facts. Interconnectivity is the big story of the digital ag.

\section{Narratives that change our world}

Narratives are now constantly fed by content creation and engagement that shape our lives. They are complex, organic entities, with their own unique behaviours and characteristics. State-of-the-art, communication science, and Big Data, can leverage social media to ensure the effective and efficient delivery of the most appropriate stories, in context, to different constituencies [2]. The ability to engage with engagement is in stark contrast to traditional media intrusion, of the mass media era. Critically, this approach indicates what people are thinking and feeling is important, to them at a specific point in time. In these unusual times with heightened uncertainty, it becomes more of an 
imperative to be able to communicate and connect in a relevant and credible way to gain trust. In many ways, COVID-19 has put all of us in our own 'Living Labs' and these analyses, leveraging the earth.ai, Big Data perspectives, provide a Virtual Living Lab [3]. Generally, most narratives (82\%) have low engagement and can be viewed as white noise (Figure 1). These are classified as transient. Those narratives that have the greatest potential utility are timeless and transformational. Timeless (5\%) narratives are expected to persist or grow. If one considers the narratives of the top 100 brands / companies then their effective communications strategies are focused. One sees timeless engagement representing atleast 90 percent of their narratives. Transformational (2\%) narratives are the core focus of this paper. They are characterised by intensely, engaged experiences with potentially strong timeless themes, explicitly providing a future orientation at scale.

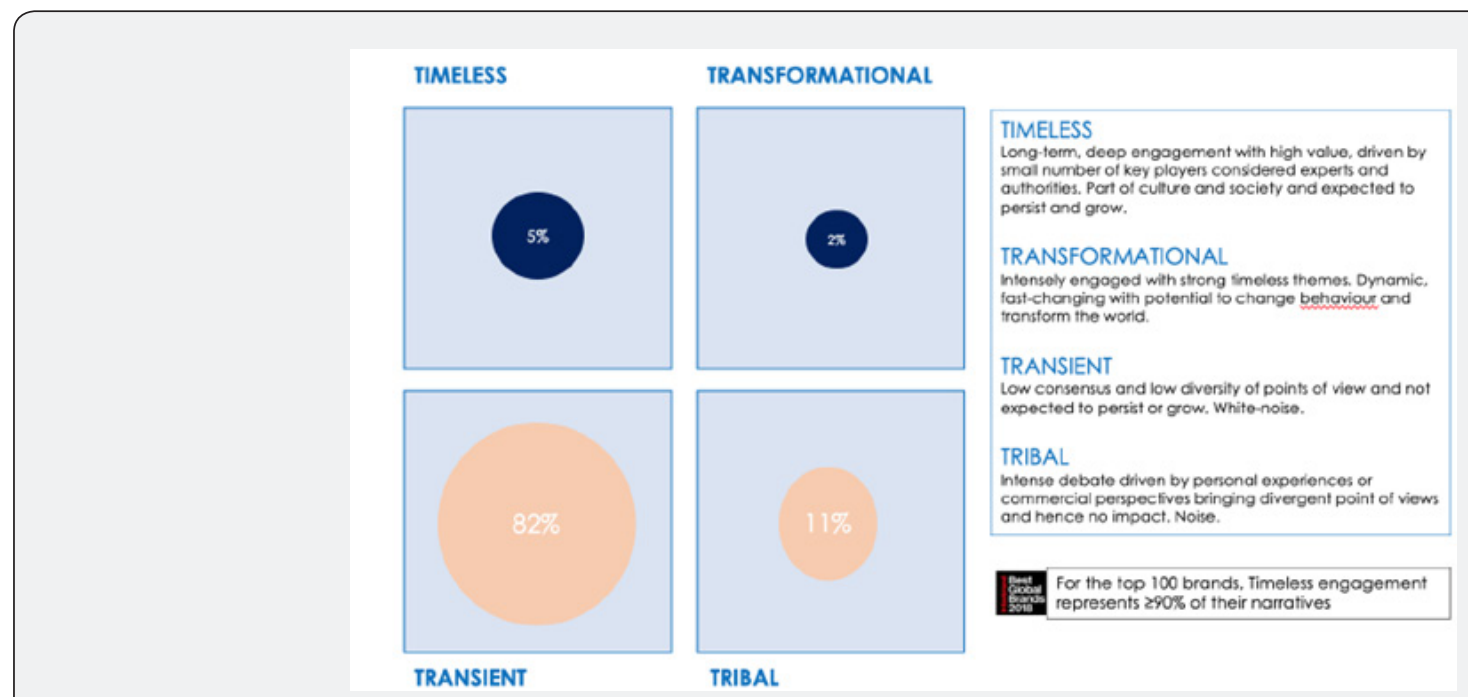

Figure 1: Narrative engagement classification landscape @Significance Systems (used with permission).

\section{Virtual Living Lab}

The lifestyle narratives (Table 1) used in these analyses were identified by subjective PreSearch of different health, lifestyle, and wellness publishing channels. This was felt most efficient in establishing a diverse, but focused group of narratives. The benchmark primary research began in June 2019, with subsequent waves in December 2019; April 2020; June 2020 and December 2020. The research covered Japan and the UK for comparative purposes. To develop the narrative landscapes, we look at all online sources, in Japan and the UK respectively, up to the date of the specific wave of research. There is no time window. Therefore, depending on the specific narrative, which self organises, it could be dominated by recent content ... or not. The April 2020 was an additional wave because, at that time, both Japan and the UK had their first, COVID-19, national emergencies in place.

In the first wave of research, in both Japan and the UK, the encouraging first observation was that most of the narratives were timeless. That said, the timeless narratives in Japan generally had content that was less well-defined, than those in the UK, on average.

Encouraged by (anti) social media, COVID-19 became an internet virus as well as a biospheric virus. There was too much disinformation, too much misinformation and information poorly organized causing confusion, paranoia and pessimism. This rapidly created unprecedented social, economic, and political challenges and social media narratives caused minds to be altered, and attitudes adjusted. The profound shift created by the pandemic is talked about in terms of different era BC, DC, and AC (Before-; During-; After-; COVID-19) [4]. Such transformational attitudes and behaviour can be tracked and evaluated, knowing what is important one can engage with timely and relevant content, in a tone that is appropriate. This is discussed in the next section.

The pandemic has heightened the review on globalization, value chain dynamics [5], and the re-evaluation is on-going [6], as nationalism and populism have been recently amplified. At the same time, it needs to be recognized that while the internet helps connectivity, in reality, because of different cultures, it creates an entanglement that needs to be simplified. Indeed, as the internet continues to entangle us all and traditional regulations fall away, and traditional institutions fail to impose moral or ethical standards then it remains an open question with whom the responsibility for developing and championing a new ethical code exists? It is unlikely that the popularity of ESG (Environmental, Social and corporate Governance) investing [7] is likely to provide a coherent and scalable set of metrics that are relevant across borders and categories.

Moreover, the pandemic has highlighted the impact of differing culture; the ethics and values that a nation adheres to helps to define its response to changes in their socio-economic environment. How the British responded to the impact of COVID-19 was different to Japanese. Relative to the UK, Japan, has 
been shown to be a much tighter society. These differences are not random [8]. In this broad international study, it is determined that 'loose cultures' had five times the number of COVID-19 cases that 'tight cultures' did, and more than eight times as many deaths.

Table 1: Lifestyle Narratives tracked in Japan and the UK.

\begin{tabular}{|c|c|}
\hline 24 Lifestyle & Narratives \\
\hline Well-being & motivation \\
\hline wellness & my community \\
\hline personal happiness & personal bonding \\
\hline personal satisfaction & being employed \\
\hline leisure time & personal wealth \\
\hline personal employment & personal relationships \\
\hline personal life balance & my resilience \\
\hline personal friendship & personal confidence \\
\hline my family & personal optimism \\
\hline personal nutrition balance & personal pessimism \\
\hline personal activity & social stability \\
\hline my free time & economic growth \\
\hline
\end{tabular}

\section{Transformational Narratives}

In general, few narratives are transformational (2\%). Such narratives are typically characterised by intensely engaged experiences with strong timeless themes. By their very nature such narratives are fast-changing, yet potentially result in lasting transformation of the world. Within such a dynamic environment they offer potent, opportunistic, themes for communications, or conversely a great threat if an opposed issue. The only transformational narrative in the first wave of research in June 2019 (BC) was My Resilience(私の回復力) in Japan (Table 2). At that time, its' affect orientation was positive and active, evidence of a delight that could be aligned with to generate some momentum. In general, most narratives are simply neutral, and do not provoke any emotional response. There is more a sense of calmness, joy and happiness than fear, with largely positive tonal cues of hope and expectation, with a sense of earnestness. The most powerful media to lead debate and perception around this narrative comes from business; businessinsider.jp and Nikkei.co.jp. The topical drivers of engagement are shown in Figure 2, which offers an understanding of the most powerful themes of the My Resilience narrative.

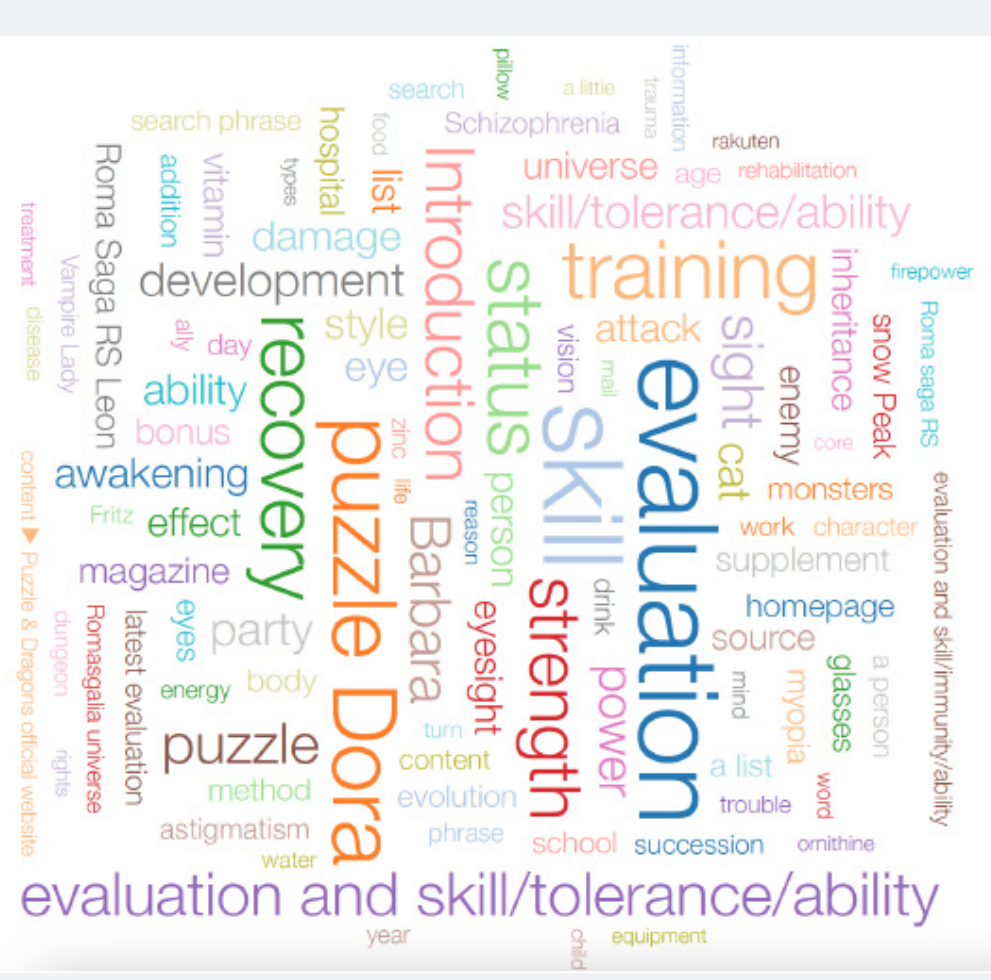

Figure 2: Relative importance of topical drivers of My Resilience (Japan; June 2019).

In contrast, My Resilience in the UK was categorized as a timeless narrative. As in Japan, the affect orientation was active and positive, with powerful content coming from several distinct media sources, including the BBC, GOV.UK, and The Wellbeing Project. In the case of the latter, people became increasingly concerned about job security and uncertain about their future employment due to Brexit, in June 2019. The emotional response at the time when compared with Japan was more negative highlighting fear, anxiety 
and distrust. As a result, it is not surprising that the important topics driving this narrative had a more community, institutional and familial support focus in the UK (Figure 3) than in Japan.

By the time of the first national emergency in Japan, due to COVID-19, in April 2020 My Resilience had become a transient narrative, still with an active and positive affect orientation such was the speed and extent of unprecedented changes in behaviour that dramatically affected work-life balance. At this time there were no clear topics and themes in the narrative and that remained the case throughout 2020 . That said, the rise in mental health concerns can be mooted for different reasons amongst different cohorts. In October 2020 the suicide rate amongst Japanese females increased by some $70 \%$ YonY [9], which was in part the reason for the creation, for the first time in February 2021, of the
Minister of Loneliness. Isolation will create many different social issues and heighten inequality.

In the UK, with the country in a national lockdown, the narrative remained timeless but there was a noticeable negative shift in the active affect orientation. This perception was being shaped by gov. uk and nhs. In terms of the topics driving engagement there was an uncertainty and expectation around work and partnership, a positive association with the NHS which contrasted with negative associations with leadership, stress and resilience itself. By December 2020, in the UK, resilience was positively associated with lives and trials against adversity, but negatively associated with work and social workers, as well as government and general security.

\begin{tabular}{|c|c|c|}
\hline Wave & - Japan & 牙UK \\
\hline 19-Jun & My Resilience & \\
\hline 19-Dec & Personal Friendship & $\begin{array}{l}\text { Personal Wealth, Personal } \\
\text { Satisfaction }\end{array}$ \\
\hline 20-Apr & Personal Friendship & Personal Friendship \\
\hline 20-Jun & $\begin{array}{l}\text { Personal Friendship, Personal } \\
\text { Bonding }\end{array}$ & Being Employed \\
\hline 20-Dec & $\begin{array}{l}\text { Personal Confidence, Personal } \\
\text { Wealth }\end{array}$ & $\begin{array}{l}\text { Personal Friendship, Personal } \\
\text { Bonding, Personal Satisfaction }\end{array}$ \\
\hline
\end{tabular}

Table 2: Transformational narratives for first 5 waves of research in Japan and the UK. (June 2019-December 2020)

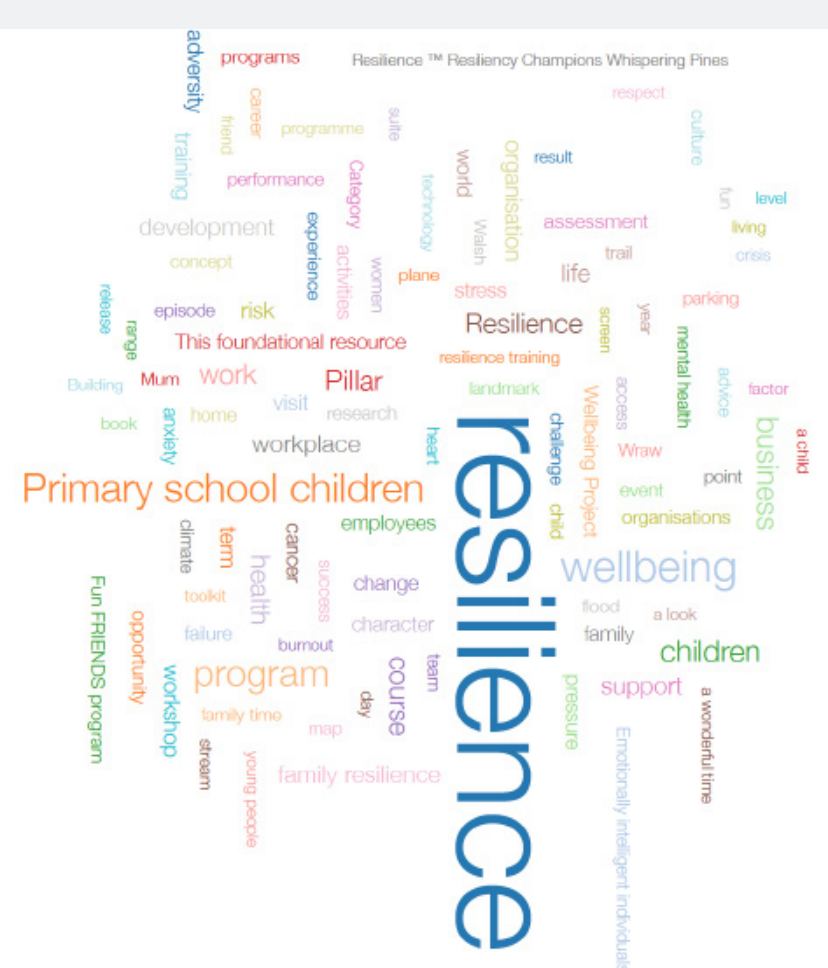

Figure 3: Relative importance of topical drivers of My Resilience (The UK; June 2019). 
During the pandemic it has been difficult to maintain relationships where, with national emergency ockdowns, people have a shared experience; 'together in being alone'. While BC our friends and friendships help to define us, with the pandemic (DC) there has been a friendship pause, My Resilience refocused, and a significant change in the number of relationships that can be nurtured. The dynamic nature of Personal Friendship, in both Japan and the UK, is evident from our analyses. This changing nature of relationships is reflected in increased loneliness, mental health concerns and new structures in peoples' social networks. COVID-19 has put key aspects of previously accepted life norms under stress, and some of these were fundamentally transformed, and still be actively assessed, such as the future of the workplace.
With new information and thinking taken onboard changes in attitude have led to changes in behaviour and orientation.

In Japan, Personal Friendship (個人的な友情) was transformational from December 2019 through to June 2020, but by the end of 2020 it had become transient, as uncertainty continues. Engagement around this topic at that time does not display a clear pattern of topics and themes. While transformational its affect orientation was active and positive. Over that time the dominant positive emotions were those of love, and happiness creating joy. At the time of the first national emergency in Japan in April 2020 it was not surprising to see a stronger dichotomy of positive and negative emotions, although the affect orientation remained active and positive.

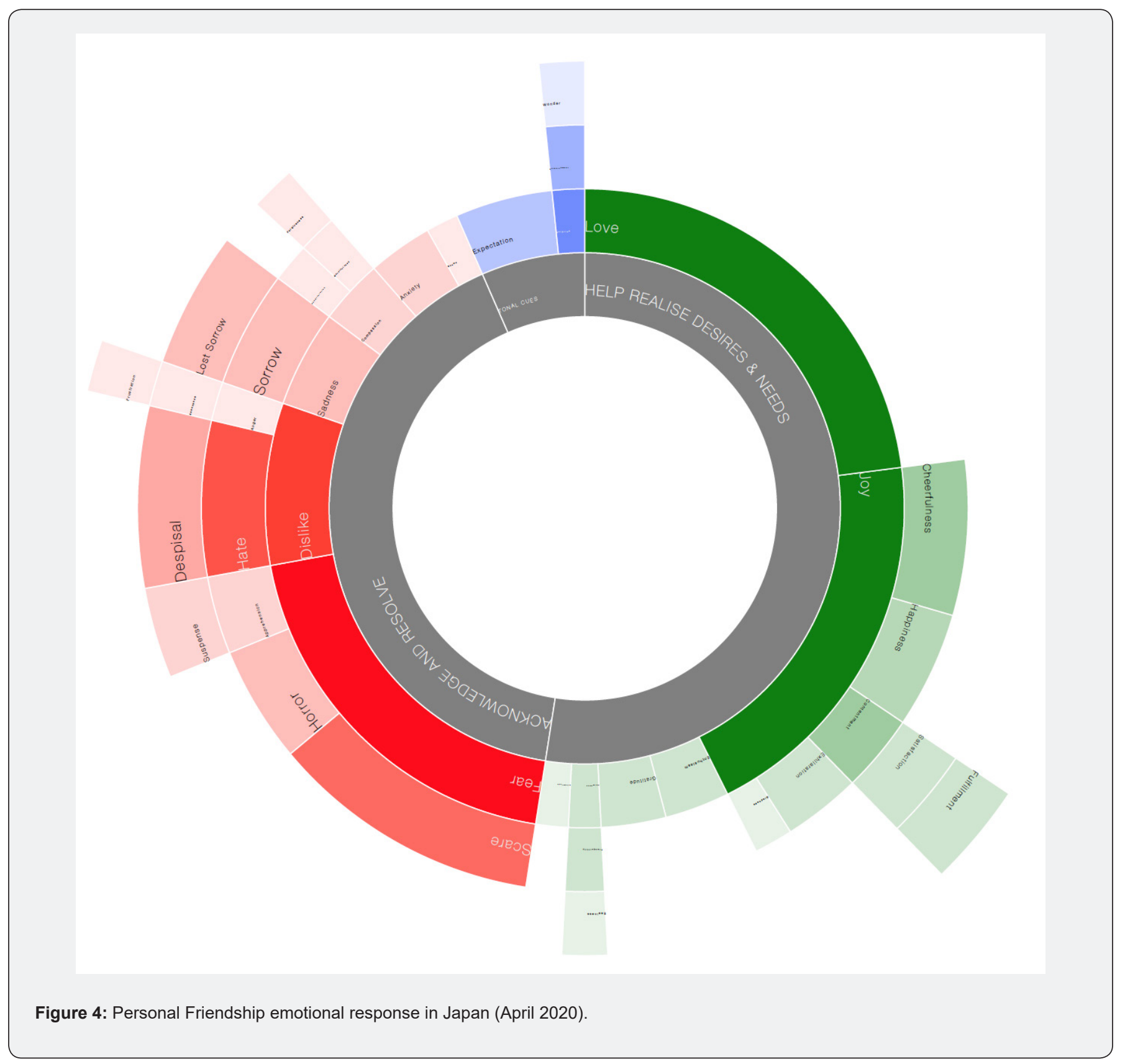


Affect is a rich measure of the emotional tone of the significant content. Understanding of the emotional drivers empower you to better understand, empower you to better understand, and respond appropriately to, the emotional impact of the narrative, content and tone. In Figure 3, positive emotions are highlighted in green, whereas negative emotions are red. From a negative perspective we witness that people feel scared and horrified by the situation which is driving their fear. If there is a clear tonality to the emotions expressed, such as expectation or apprehension, these are shown in purple. The intensity of the colour indicates the intensity of each emotion. The width of each arc reflects the degree to which the named emotion contributes to the overall emotional response. Broad emotions, such as fear and love, are closer to the centre of the chart. The more subtle emotions, which contribute to those broad emotions, are shown in the concentric rings further out. Moving out from the centre, each ring shows a further level of detail. In the UK, in April 2020, there was a national lockdown. The strength of the emotions, whether positive projecting a sense of calm or negative (panic and fear), around Personal Friendship were much weaker than in Japan at the same time (Figure 4). The effect and support were the key positive topics within the Personal Friendship narrative. They created an overall sense of anticipation, while discussion of disability was viewed with a more negative association. Here the focus of concern was moved, in the UK, to the PIP benefit (Personal Independence Payment) which was replacing the DLA (Disability Living Allowance) (Figure 5).

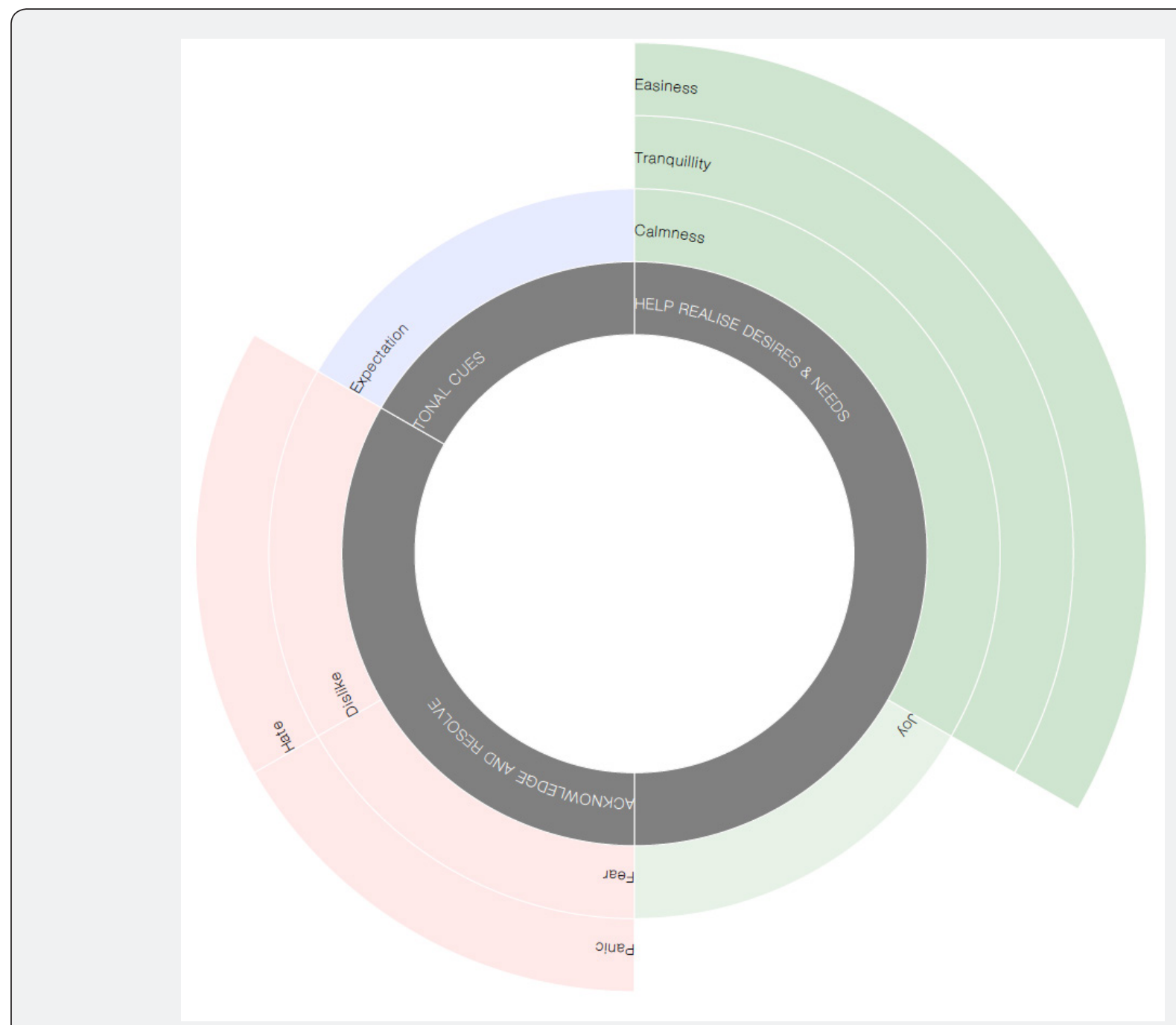

Figure 5: Personal Friendship emotional response in the UK (April 2020).

\section{Implications}

COVID-19 is first a human tragedy, and we are witnessing in this Virtual Living Lab universal human values of love, purpose, that can often bring us together. This common ground offers effective messaging opportunities. Personal Friendship is being redefined as a sense of being able to belong is heightened. There is perceived safety in belonging and the imperative is to remain part of the group. We should reiterate that these analyses are not just identifying some interesting things but things that are important 
to people now! While fast-forwarding our digital futures, the pandemic is amplifying emotions, and compelling us to re-examine ourselves, our values, and our institutions. It is also demanding we act at speed in a focused, credible and relevant manner.

By holistically, tracking the narratives that are shaping our world we can 'engage with engagement'. This provides actionable utility as briefly illustrated in this paper:

$\sqrt{ }$ Engagement Classification: assess where opportunities exist to annex timeless and transformational narratives

$\sqrt{ }$ Affect Orientation: to understand the emotional response of the narrative

$\sqrt{ }$ Media Power: identify and rank media by their power to influence the narrative

$\sqrt{ }$ Content Power: assess the power of individual pieces of content to influence the narrative

$\sqrt{ }$ Emotional Response: understand how the emotional tone of the significant content

$\sqrt{ }$ Relationships: confirm the interconnectivity of topics and themes to enhance relevance and credibility

A vireal (virtual and real-world), concern about being on 24/7 and work-life balance took on new meaning when home schooling and teleworking became a necessity. The pandemic has for many accelerated the future of work with perceived productivity and flexibility benefits. The culture of work is likely to be permanently transformed for many and that may well affect aspirations and reframe beliefs. In a disruptive age, with established business models are under attack, leaders cannot lose sight of the need to motivate staff and nurture their corporate culture. The impact of the new and evolving situation has not impacted everyone in the same way. While some commentators are talking about broader based and new mental health concerns lingering long into a move DC-->AC, it has already been noted in Japan, that the significant, declining trend, over recent years, in suicides has been reversed by the national emergency especially amongst young females [9].

Isolation can also be impacting the workplace and exacerbating personal stress. Moreover, social distancing can inhibit innovation, as proximity sparks casual conversations that are necessary to build empathy, trust, and team, which stimulate co-creation and transformation. Remote, rigid agendas within 'Zoom' / 'Teams' can give an illusion of effect, in the short-term, but the long-term opportunity is to empower and humanize agile work environments. That said, with apparently endless video calls becoming the 'new norm', researchers at the Stanford Virtual Human Interaction Lab [10], have recently commented on 'Zoom fatigue' resulting from "excessive amounts of close-up eye gaze" and "increased self-evaluation from staring at video of oneself".

Time poverty still prevails, and people will increasingly reject the complex. Streamlining is characterized by a shift away from living in the future to living in the present as people grapple with work-life demands that are in disequilibrium. Inspiration needs to be rooted in stories that are authentic, drawing on cultural and social mores, yet that envision a future that can create a personal style rooted in evolving authenticity. When lives are being turned upside down and continued uncertainty magnifies the tension it has never been more important to be able to 'engage with engagement'. Thus, it is possible to make your point (educate) within narratives that are transforming and engage with a receptive and open mindset.

With ever more information, and provocation, there is a glaring lack of adequate dialogue and the pandemic has put trust to the test, with governments consistently losers [11]. With so much noise, it is more difficult to get the signal, but the takeaway is that I am not listened to. There is no return to business as usual in the foreseeable future. It raises two critical questions for public and private enterprises alike, and social media will not let you hide. What is the game plan? What exactly should enterprises communicate to people? As such, from either a corporate or public policy perspective aligning with such stories that the people feel are driving their current feelings would resonate as a Thoughtful Leadership stance as societal health concerns rise up the agenda. The imperative has become how we can make sense in an era of disinformation and panic by offering clarity and being positive. Coming out of the pandemic and moving DC-->AC will demand regaining trust is paramount as it is amplified in a social setting.

As we look to the future, we should support the things that bind us together, and invest in our communities at scale. public and private institutions will need to accelerate digital investments and participation in ecosystems, where aligning with the ongoing narratives is likely to become even more important, and aid how we evolve the agile practices adopted during the crisis. The recovery will not be a straight line, nor will it be on the same timetable in different countries / regions. Whatever the cultural traits, there is a need for optimism as we evolve from DC-->AC. There must be a positive tone to the messages and transformative collaboration can lead to improvements in QOL and productivity.

At a time of unprecedented change due to COVID-19, poor communications have prevailed leading to unnecessary fear and suffering [3]. Too much disinformation, too much misinformation and information poorly organized creating confusion, and pessimism. Entropy is increasing at a time when clarity, optimism and conviction are demanded. This paper has outlined an improved process to identify common ground objectively and rapidly, that can be readily scaled to enable better communications. As countries begin to roll-out their vaccination programmes this will be important to ensure expectations are realistically communicated. By explicitly focusing on transformational narratives, one has a natural orientation to future policy, facilitating leadership, decision-making, at scale. 


\section{References}

1. Shiller J (2019) Narrative Economics: How Stories Go Viral and Drive Major Economic Events, Prince town University Press, USA.

2. Beaumont CD, Ricketts J, Berry D (2021) Tracking Narratives that are Shaping Our World. Int J Environ Sci Nat Res 27(1): IJESNR. MS.ID.556202

3. Beaumont CD, Ricketts J (2020) A Significant Moment in History: a virtual Living Lab., LifeStyle narratives that are shaping our world; the cases of Japan and UK 2019-20. Sustainability 12(22): 9658.

4. Nelms B (2020) Special Issue: Big Data, Knowledge Management and IoT: New Perspectives for New Challenges in Disruptive Times. BC, DC and $\mathrm{AC}-$ The heroes rarely mentioned, The Citizen.

5. McKinsey Global Institute (2019) Globalisation in transition: the future of trade and value chains.
6. Imperial Business Insights, Leadership Strategy, Does COVID-19 mean the end of globalization? 2021, Forbes.

7. Bhat OV (2021) The Rise of ESG Investing Value Research, Fundwire

8. Gelfand M J, Joshua Conrad Jackson MA, Xinyue Pan BS, Prof Dana Nau, Dylan Pieper MA et al., (2021) The relationship between cultural tightness-looseness and COVID-19 cases and deaths: a global analysis, Lancet Planet Health.

9. BBC (2021) Covid and suicide: Japan's rise a warning to the world?

10. Bailenson J (2021) Nonverbal Overload: A Theoretical Argument for the Causes of Zoom Fatigue, Technology, Mind and Behaviour, 2 (1).

11. Edelman Trust Barometer (2021) Global Report, online fieldwork in 28 countries between October $19^{\text {th }}$ to November $18^{\text {th }}$.

\begin{tabular}{l} 
Your next submission with Juniper Publishers \\
will reach you the below assets \\
- Quality Editorial service \\
- Swift Peer Review \\
- Reprints availability \\
- E-prints Service \\
- Manuscript Podcast for convenient understanding \\
- Global attainment for your research \\
- Manuscript accessibility in different formats \\
( Pdf, E-pub, Full Text, Audio) \\
- Unceasing customer service \\
Track the below URL for one-step submission \\
https://juniperpublishers.com/online-submission.php \\
\hline
\end{tabular}

